\title{
COVID-19 in LMICs: The Need to Place Stigma Front and Centre to Its Response
}

\author{
Keetie Roelen ${ }^{1}$ (D) Caroline Ackley $^{2} \cdot$ Paul Boyce $^{3} \cdot$ Nicolas Farina $^{4}$. \\ Santiago Ripoll ${ }^{1}$
}

Accepted: 7 October 2020 / Published online: 21 October 2020

(c) European Association of Development Research and Training Institutes (EADI) 2020

\begin{abstract}
COVID-19 has caused unprecedented health, economic and societal impacts across the world, including many low- and middle-income countries (LMICs). The pandemic and its fallout have laid bare deep-seated social and economic inequalities with marginalised groups being at greater risk of infection and being disproportionately affected by containment measures and their socioeconomic consequences. Stigma is a central element to such inequalities but remains largely overlooked in the debate on the response to COVID-19, including in LMICs. Yet we know from experiences with other infectious diseases such as HIV/AIDS and Ebola that disease-related stigma is detrimental to halting and controlling pandemics and achieving equitable development. Emerging evidence suggests that stigma associated with COVID-19 is already taking hold. This paper assesses potential driving factors of COVID-19-related stigma, and how this intersects with existing stigma fault lines and explores mechanisms through which COVID-19-related stigma may be counteracted, with a focus on LMICs.
\end{abstract}

Keywords Stigma $\cdot$ COVID-19 $\cdot$ Coronavirus $\cdot$ Pandemic $\cdot$ Disease-related stigma Development · LMICs

\section{Résumé}

La COVID-19 a eu un impact sanitaire, économique et sociétal sans précédent à travers le monde, y compris dans de nombreux pays à revenu faible ou intermédiaire (PRFI). La pandémie et ses retombées ont mis à nu de profondes inégalités sociales et économiques, les groupes marginalisés étant plus exposés au risque d'infection et étant touchés de façon disproportionnée par les mesures de confinement et par leurs conséquences socioéconomiques. La stigmatisation est au centre de ces inégalités mais reste largement négligée dans les débats sur la réponse à la COVID-19, y compris dans les PRFI. Grâce à l'expérience que nous avons sur d'autres maladies infec-

Keetie Roelen

k.roelen@ids.ac.uk

Extended author information available on the last page of the article

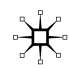


tieuses telles que le VIH/SIDA et la maladie à virus Ebola, nous savons pourtant que la stigmatisation liée à une maladie empêche de contrôler et de stopper les pandémies et ne permet pas un développement équitable. De nouvelles preuves suggèrent que la stigmatisation associée à la COVID-19 gagne déjà du terrain. Cet article évalue les facteurs potentiels de stigmatisation liée à la COVID-19, analyse comment cela se recoupe avec les failles existantes de la stigmatisation et explore les mécanismes par lesquels on peut lutter contre la stigmatisation liée à la COVID-19, en mettant l'accent sur les PRFI.

\section{Introduction}

Since its onset, experiences with COVID-19 in China, Europe and the United States provide clear testimony of its far-reaching health, economic and societal impacts. It is becoming increasingly clear that the pandemic's consequences are likely to be even graver in many low- and middle-income countries (LMICs). Higher transmissibility due to overcrowding in densely populated areas, larger household sizes and poor quality of water and sanitation, higher infection-to-case ratios due to high prevalence of comorbidities such as hypertension and diabetes, and higher fatality rates due to lack of health care capacity contribute to more severe health consequences in LMICs (Dahab et al. 2020). Lockdown measures and restrictions on movement that have been put in place to quell infection rates also have far-reaching adverse effects. Large proportions of the workforce in the informal labour market are left without any source of income and informal supply chains are disrupted (Kelley et al. 2020). Negative health and economic consequences are exacerbated by limited coverage of social protection (Lind et al. 2020). Lack of income support makes it more difficult to adhere to physical distancing by foregoing work outside the home. Estimates suggest that the number of people expected to fall into extreme poverty ranges anywhere between 80 and 395 million (Sumner et al. 2020).

To date (in September 2020), policy measures have focused on providing shortterm economic relief for those most vulnerable (Gentilini et al. 2020) and on developing a vaccine that is available and affordable for all (Usher 2020). However, as experiences with HIV/AIDS, Ebola, cholera and other transmissible diseases have highlighted, responses to pandemics often suffer from a narrow biomedical focus and overlook the social, economic, political and cultural contexts in which they take place (Kelley et al. 2020). This limits understandings of how disease might spread, who is affected and how, and how policies should be shaped to offer the most effective and equitable response. This is no different for COVID-19: the sheer scale of the pandemic, the speed at which it continues to spread and the urgency with which response measures are being put in place means that socioeconomic dynamics and inequities receive relatively little attention (Kelley et al. 2020). Moreover, LMICs' replication of policies that originate from high-income countries call into question the extent to which such policies are adequately contextualised and pay attention to existing patterns of socioeconomic injustice (Barnett-Howell and Mobarak 2020; SSHAP 2020). 
Stigma is integral to patterns of injustice, and experiences with other pandemics highlight that paying heed to stigma is vital for providing an effective and equitable response to COVID-19. Long-standing research on HIV (Mahajan et al. 2008; Castro and Farmer 2005) and neglected tropical diseases (NTDs) (Hofstraat and van Brakel 2016) as well as more recent experiences with Ebola (Karamouzian and Hategekimana 2014) indicate that stigma is experienced by those being affected by disease (both directly or indirectly, such as survivors or health workers) or by groups that may be seen as 'vehicles' for, or most structurally vulnerable to, infection. Stigma also intensifies along fault lines such as class, age, gender and race (Lerman et al. 2017). Stigma is detrimental to halting and controlling pandemics, to support societies' recovery from a pandemic, and achieving equitable development. It puts up barriers to accessing health care and social services, impedes healthseeking behaviour, undermines adherence to treatment and leads to social exclusion, discrimination, mental distress and-in some cases-violence (Rohrwerder 2018; Stangl et al. 2019; Roelen 2020). Although COVID-19 is still relatively new, the many unknowns and uncertainties associated with this 'newness' may give rise to fear that can in turn fuel stereotyping and stigmatisation (WHO 2020). Indeed, stigmatisation of those infected with or having survived the virus as well as health workers who face high exposure is already mounting (Bagcchi 2020; United Nations 2020a; Taylor 2020).

The objective of this paper is twofold. First, we assess potential driving factors of COVID-19-related stigma, and how this intersects with existing stigma fault lines. Second, we explore mechanisms through which COVID-19-related stigma may be counteracted and prevented. We do so by taking an interdisciplinary approach and building on well-established research on disease-related stigma in relation to pandemics such as HIV, NTDs and Ebola as well as literature on stigma associated with old age, disability and poverty.

The remainder of this article is structured as follows: First, we provide a conceptual framework to underpin our analysis of COVID-19-related stigma. Second, we assess driving factors that contribute to COVID-19-related stigma. Third, we explore fault lines that intersect with and compound COVID-19-related stigma. Fourth, we explore ways in which such stigma may be avoided in the response to COVID-19. Finally, we offer critical reflections for future action.

\section{Framing Stigma}

In his seminal work on stigma, Goffman (1963) posits that stigma denotes an attribute that is discreditable, leading to a 'spoiled identity'. Stigma represents a characteristic that is different from 'normal' and triggers disapproval or devaluation in certain social contexts (Bos et al. 2013; Link and Phelan 2001) with those being stigmatised somehow deemed to be less human (Goffman 1963). Stigmatisation constitutes others' responses to stigma and can be overt, such as avoidance and humiliation, as well as more subtle, including lack of eye contact (Bos et al. 2013). This, in turn, interacts with 'potential internalization of the negative beliefs and feelings associated with the stigmatised condition' (Bos et al. 2013), understood as 
self-stigma, internalised stigma or shame. One can also distinguish between 'existential' and 'achieved' stigma (Falk 2001). Existential stigma derives from a condition that is mostly outside of the control of the target of the stigma, while achieved stigma applies to those "who have earned a stigma because of their conduct and/or because they contributed heavily to attaining that stigma' (11).

Stigma has far-reaching intrapersonal, interpersonal and societal consequences, ultimately undermining efforts to counteract pandemics and promote equitable development. It leads to social isolation, hampers access to care, and reduces treatment adherence (Mulea et al. 2009). During the Ebola pandemic in western Africa from 2014 to 2016, Ebola patients, survivors and orphans (and on occasion their relatives), as well as health workers involved in the response faced "shunning and isolation, ill-treatment, [and] the rejection of treatment and political or economic exclusion" (ERAP 2014, p. 1). Fear of stigma led Ebola-affected families to hide symptoms from their communities and health services (Hewlett and Hewlett 2008). Similar reports emerged from survivors and health workers as a result of the SARS pandemic in some Asian countries (Lee et al. 2005; Verma et al. 2004). There is also published evidence of widespread stigma related to NTDs such as lymphatic filariasis, podoconiosis, Buruli ulcer, onchocerciasis, leprosy, and leishmaniasis (Hofstraat and Brakel 2016, p. 65).

These examples of disease-related stigma can be linked to Goffman's notion of 'spoiled identity'. A common critique of Goffman's theory, however, is that it provides an apolitical understanding of stigma, placing the onus of being 'discredited' on those that are stigmatised. Instead, as pointed out by scholars across the health and social sciences, stigma takes hold and is perpetuated within a social context with inherent power structures, serving to put in place and maintain hierarchies and social order (Link and Phelan 2001; Tyler and Slater 2018; Parker and Aggleton 2003). Building on conceptualisation of stigma within the field of HIV (Earnshaw et al. 2013), COVID-19-related stigma can be understood as a social phenomenon whereby people infected with or affected by COVID-19 are labelled, stereotyped or discriminated against and that intersects with existing fault lines of socioeconomic disadvantage, thereby perpetuating and reinforcing power structures and structural inequalities. Stigma is the visible 'tip of the iceberg' of much wider systems of beliefs about who carries disease and why that are grounded in and compounding social inequalities (Castro and Farmer 2005).

The Health Stigma and Discrimination Framework by Stangl et al. (2019) helps to ground understandings of stigma within a wider context and to map the process from drivers and facilitators of stigma through to outcomes of stigma. Drivers of stigma tend to be specific to the health condition, including fear of infection, lack of awareness, stereotypes and prejudice. Facilitators of stigma apply more broadly and include social and cultural norms, levels of inequality and legal and policy environments. The health-related stigma itself intersects with other stigma 'markers' such as age, gender, race and class. This then leads to experiences, manifestations and outcomes at individual, societal and institutional levels, ranging from internalisation of stigma to social exclusion and institutionalised discrimination (Stangl et al. 2019).

The framework's multi-layered focus and the way in which it locates the process of stigmatisation within the wider socioeconomic context makes it particularly 
useful for coming to grips with the unfolding and evolving nature of COVID-19-related stigma in LMICs. It affords an opportunity to move away from biomedical explanations of how the pandemic may evolve and provides a biosocial perspective. Experiences in relation to HIV and AIDS have evidenced the importance of understanding social, economic and political processes surrounding disease in order to create an effective response (Castro and Farmer 2005). Given the evolving nature of the pandemic and its drivers, dynamics and manifestations, we zoom in on emergent driving factors of COVID-19-related stigma and fault lines along which existent stigma may be reproduced and compounded.

\section{Driving Factors of COVID-19-Related Stigma}

Based on a review of stigma in relation to other transmissible diseases, attributes such as old age, disability and poverty and unfolding knowledge about COVID19-related stigma, we identify three interrelated driving factors.

\section{Lack of Information and Misconceptions}

First, lack of information, misinformation and misconceptions serve as key conduits for stigma, often assigning blame for disease. Whilst biomedical explanations may be widely available, alternative explanations or misinformation may emerge with specific individuals being singled out as causes or carriers of disease, playing into 'achieved' stigma. For example, during previous Ebola outbreaks in the Democratic Republic of Congo (DRC), the disease had been attributed to witchcraft or sorcery, supposedly enacted by those who were perceived to 'benefit' from a patient's death, widows or mothers of the diseased, or people who are seen as outcast and in contact with non-natural forces (Ripoll et al. 2018). In Pakistan, the general public incorrectly identified dementia symptoms as a normal part of aging, or perhaps more concerning, that it is attributable to the actions of the individual. The latter inevitably led to people believing that the person with dementia should be responsible for their own healthcare and outcomes (Boyce and Cataldo 2019). Similar dynamics have been observed in relation to disability with cultural and religious beliefs playing into false perceptions about causes of disability (Rohrwerder 2018). Across Africa, stigma-inducing beliefs include disability being caused by ancestral curses or transgressions in previous generations, demonic possession and supernatural or otherworldly interference, promiscuity or other sinful behaviour by the mother or other family member or a punishment for wrongdoing by the person with a disability (ibid). Stigma may also arise from beliefs that people with a certain condition pose a burden to society. These experiences are clearly visible in relation to disability with low (and often misplaced) expectations about how people with disabilities can or cannot contribute to society leaving them labelled as less able or productive (Rohrwerder 2018). They also play out in relation to poverty, with people in poverty being blamed for their predicament on presumptions of laziness or unwillingness to work (O’Hara 2020). 
Misinformation and misconceptions in relation to COVID-19 are already widespread. For example, in Ghana there was a voice recording where it was believed President Nana Akufo-Addo was endorsing numerous false conspiracies, including the claim that the pandemic was a planned event. Ghana's Information Minister has confirmed the voice on the recording is not that of the president (BBC News 2020). In Nigeria and Sudan politicians, have been seen wearing 'protective badges' that are marketed as 'virus blockers' or 'virus stoppers'. It is claimed the badges kill viruses and bacteria by releasing a type of bleaching agent, but experts report that such 'blockers' do not work and could actually cause harm (ibid).

There are still many unknowns about the virus (WHO 2020), offering fertile feeding ground for misconceptions and alternative explanations. Internet and social media are widely used to obtain information about COVID-19 but often information is of low quality (Cuan-Baltazar et al. 2020). The WHO has referred to an infodemic' to denote the excessive volume of information that is available (Barua et al. 2020), much of which is incorrect (Erku et al. 2020). There is some suggestion that the spread of misinformation may be larger in LMICs (Wajahat Hussain 2020), possibly due to greater reliance on social media for information and lower capacity for fact-checking. Misinformation about COVID-19, including about its origin, spread and treatment, is widespread across Africa, hampering an effective response and risking demonisation of those infected (Ahinkorah et al. 2020). BBC News Africa has launched a COVID-19 misinformation hub, offering a service that fact-checks and debunks false information about the pandemic (BBC News Africa 2020).

\section{Fear of Contagion}

Second, fear of contagion is a significant driver of prejudice, stereotyping and stigmatising behaviour. This has been widely observed as in relation to disability (Rohrwerder 2018) and NTDs (Hofstraat and van Brakel 2016). Widespread anxiety about the cause and spread of SARS constituted an important mechanism for stigma to take hold at the time of the outbreak in Asia in the early 2000s (Person et al. 2004). In China, fear of contracting HIV was an important source of stigmatising attitudes associated with HIV and AIDS among rural-urban migrants (Hong et al. 2008). This also relates to 'existential' and 'achieved stigma'; disease-related stigma is often related to the extent to which the person being stigmatized is deemed at fault for having contracted the illness if their behaviour contributed to infection. Such 'victim-blaming' has been widely observed in relation to HIV and AIDS, including in the Caribbean (Castro and Farmer 2005).

The infectious nature of COVID-19 and its potentially life-threatening consequences coupled with ubiquitous updates about infection and fatality rates leads to high levels of anxiety, stoking fear of infection (Basu 2020). Already examples are emerging of how such fear leads to prejudice, avoidance and demonisation among those having been infected with or having survived COVID-19. In Ecuador, the family of the first person having contracted the virus fell victim to a harsh social media campaign, accusing them of irresponsible behaviour (Armario 2020). In Indonesia, names of the first few cases were leaked online, with one woman being falsely blamed for having contracted the 
virus due to selling sex to a foreign client (ibid). In Kenya and Zimbabwe, survivors of COVID-19 were shunned by their communities after having returned from hospital for fear of them infecting others (Soi 2020; Bagcchi 2020). In Bangladesh and India, social shunning of those (suspected of) being infected with COVID-19 reportedly led to suicide (Mamun and Griffiths 2020). Healthcare workers around the world, including in LMICs, also face harassment and stigmatisation, largely out of fear for infection (Sotgiu and Dobler 2020; Taylor 2020). In Mexico, doctors and nurses reportedly used bicycles to travel to and from work as they were denied access to public transport; in India, healthcare workers have been asked to vacate their rental homes and face social isolation (Bagcchi 2020).

\section{Targeted Policies}

Third, policies that single out and separate vulnerable groups and the narratives that underpin them often inadvertently act as conduits for stigma. Such policies are the most visible way of labelling those who are 'deviant' and distinguishing them from the rest of society who are deemed 'normal', laying the foundation for legitimisation and institutionalisation of stigma (Falk 2001). The cholera response in Brazil, for example, unwittingly 'earmarked' specific communities or persons as foci of disease transmission through their targeting, treatment and risk communications strategy (Nations and Monte 1996). In relation to disability, there is a long history of segregating people with disabilities from the rest of society by placing them in institutions, leading to perpetuation of negative stereotypes (Rohrwerder 2018). With respect to old age, there are stereotypes that older adults are weak and need help (Coudin and Alexopoulos 2010), feeding into a notion that elderly persons represent a burden to society. Support to people in poverty is commonly targeted on premises of 'deservingness'(Van Oorschot 2002), leading to a toxic narrative about who should get what and why (or why not) (O'Hara 2020).

Many policies that seek to contain the spread of COVID-19 rely strongly on practices of singling out, separating and labelling, thereby laying the foundation for stigma. Quarantine, a measure that has also been used in Ebola and SARS outbreaks, is likely to feed COVID-19-related stigma (Brooks et al. 2020). In India, air crew staff felt stigmatised after health authorities stamped 'quarantined' on their houses (Krishnatray 2020). Gender-based physical distancing measures may also bring to the light people's sexual orientation or non-conforming gender identities, putting them at risk of harassment and prejudice. In Colombia, measures to limit the number of people on the streets allowed men and women to go outdoors for essential tasks on alternate days, leaving trans people at risk. Multiple reports of abuse and violence against trans people were reported (Griffin and Antara Rivera 2020). 


\section{Fault Lines for COVID-19-Related Stigma}

Disease-related stigma does not stand on its own and interacts with other fault lines, layering onto already existing processes of discrimination and marginalisation and leading to intersecting or co-stigmas. For example, when cholera reemerged in Latin America in the 1990s, the disease was attributed to poor people, who had been previously neglected and marginalised by the state in terms of provision of basic water and sanitation infrastructure and health services. Cholera was also racialised, and poor black and indigenous people were 'othered' as dirty or filthy (Briggs and Mantini-Briggs 2003; Nations and Monte 1996). Those living in informal settlements were unable to implement the government guidelines on cholera, because of inadequate infrastructure (e.g. water points and soap) (Ripoll 2017). In China, HIV/AIDS-related stigma was found to co-exist and interact with commonly associated stigma attached to injection drug use and commercial sex (Chan et al. 2007).

Across LMICs, we can also see such fault lines emerging that make certain groups more vulnerable to COVID-19-related stigma. We identify four main fault lines.

\section{Poverty and Informality}

First, people living in poverty, precarious conditions or informal settlements are at a heightened risk of COVID-19-related stigma. Poverty and deprivation itself is a potent trigger for stigma, leading to internalisation of stigma and shame (Walker 2014). This in combination with the many difficulties that people in poverty and precarious conditions face in adhering to distancing measures provides a potent mix for stigma. Guidelines on hand hygiene, physical distancing or lockdown are often not plausible in densely populated, informal and impoverished contexts due to crowding, insufficient water and sanitation services and low and precarious incomes (Wilkinson 2020). Similarly, farm workers, refugees and people living on the street are both less able to adhere to lockdown and physical distancing measures while also more affected by those measures (Devereux et al. 2020). This makes them vulnerable to negative stereotyping and being labelled as vehicles of infection, which compounds stigma that pre-dates COVID-19 (Logie and Turan 2020).

\section{Ethnicity, Origin and Nationality}

Second, ethnicity and nationality represent important fault lines for COVID19-related stigma. Blaming a 'foreign other' for the outbreak of disease is commonplace in order to make sense of and distance oneself from disease (Logie and Turan 2020). For example, during the 2018 Ebola outbreak in DRC, the Twa indigenous group was singled out by the majority Bantu community as transmitters of the disease, and experienced discrimination in their access to health 
services (Duda et al. 2018). Stigmatisation of Asians, or anyone deemed of Asian origin, was widespread in North America and Europe in relation to SARS and Avian Flu (Lynteris 2019; Rafi 2020; Person et al. 2004).

Similar co-stigma is likely to occur in relation to COVID-19. The fact that the virus first emerged in China has given rise to or compounded pre-existing negative attitudes, discrimination and xenophobia directed at Chinese people or those who are perceived to be of Asian descent in many high-income countries, such as Canada (NCCDH 2020). Few reports of Sinophobia in relation to COVID-19 have emerged from across LMICs, although experiences involving Chinese nationals in Uganda indicate that mistrust based on assumed nationality and origin is on the rise (Oryem 2020). Instead, a more disparate group of people 'on the move' have been stigmatised for spreading the virus. Depending on who and where these groups are, this may be associated with ethnicity, nationality or place of origin (United Nations 2020a). In Mozambique, for example, mine workers who migrated back home from South Africa were met with suspicion when integrating back into their communities (UN Department of Global Communications 2020). Finally, with a growing evidence base now indicating that Black, Asian and Hispanic patients are at a higher risk of contracting COVID-19 (Pan et al. 2020), ethnic minority is further compounded as a co-stigma.

\section{Age}

Third, age — and old age in particular — is likely to emerge as a fault line for COVID19-related stigma. Deaths associated with COVID-19, disproportionately occur in older adults (Jordan et al. 2020; Zhou et al. 2020). This can be attributed to older adults having increased likelihood of underlying health conditions such as diabetes and cardiovascular disease (Suastika et al. 2012), hypertension (Buford 2016), and respiratory problems (Buist et al. 2007), all of which increase the risk of COVID19-related deaths (Wu and McGoogan 2020; Zhou et al. 2020). In addition, ageing results in a general decline in immune responses (Weiskopf et al. 2009), making older adults more vulnerable to such viruses. As such, it is unsurprising that many health policies are put in place to protect this group.

However, this focus on old age as a factor of vulnerability is likely to compound existing patterns of ageism. In Kenya, ageism has led to the marginalisation, loss of power and dignity of older adults, opening the way to elder abuse (Kabole et al. 2013). Within LMICs more broadly, older adults describe that they are being denied autonomy related to finances, work, family life and their everyday activities (HelpAge International 2018). Governments may not have the healthcare and support systems in place to support older adults, further restricting older adults' choices. This in itself may reflect structural discrimination, as age limits imposed by global health policy and targets may lead to governments not allocating health resources to older adults (Lloyd-Sherlock et al. 2016).

Current literature from HICs indicate that a significant minority of public discourse about older adults and COVID-19 express ideas that older people are less valuable or that they should just be isolated (Xiang et al. 2020). Such narratives, 
particularly when perpetuated by those in power, could lead to policy that isolates older adults and discriminates against their basic human rights (Ayalon 2020). Lack of health care capacity to provide care for all patients and has led to debates about who should be prioritised for treatment, often finding younger people more 'deserving' (Logie and Turan 2020) Whilst ageist issues exist in LMICs, such as in Ghana (Gyasi 2020) and Kenya (Kabole et al. 2013), there is a dearth of data derived from these regions. Cultural differences and government responses to the pandemic are likely to drive how COVID-related stigma may (or not) form in relation to age. For example, within China a key theme from social media discourse was that older adults were still seen as "contributing to the community", with views of warmth and competence during the pandemic (Xi et al. 2020).

\section{Gender and Sexualities}

Fourth, gender and sexualities are emerging as important fault lines for COVID19-related stigma. In many countries, LGBTI people have previously been blamed for disasters or disease. In Bhutan, for example, transgender women were held responsible for natural disasters (Chuki 2019). In Zimbabwe, LGBTI people affected by HIV and AIDS were blamed for their illness and for placing a curse on their family (Hunt et al. 2017).

Reports are already emerging of such blaming taking place in relation to COVID19 , such as in Israel where one Rabbi propagated coronavirus as the revenge to gay parades and in Iran where a Shia cleric warned that the pandemic would not subside as long as same-sex marriages were legal in Iran (United Nations 2020b). The United Nations has also highlighted that surveillance and control of populations in order to contain the virus can galvanise oppression of sexual and gender minority peoples (United Nations 2020a), often in settings where transphobic and homophobic actions are already prevalent. In Uganda, for example, police reportedly used laws that prohibited more than 10 people gathering in public to arrest 23 people living in a sheltered housing project for LGBTI people (United Nations 2020b). A study among young people in Asia and the Pacific found that those who identified as LGBTI individuals or members of the transgender community were more likely to experience stigma during the pandemic (UNAIDS 2020).

\section{Countering Stigma}

There is a wide and well-established body of literature that assesses the role and effectiveness of interventions to counter disease-related stigma. These interventions engage at the intrapersonal level—seeking to counter internalised stigma-as well as at interpersonal and community level. With respect to NTDs, these commonly include self-care and self-help (Pryce et al. 2018), educational programmes (Correia et al. 2019), assistive technology (Maia et al. 2016), and community engagement approaches (Jung et al. 2020). Other measures against stigmatisation tend to be health education for patients and the community (Zeldenryk et al. 2011) and disease 
management, yet the effectiveness of these measures has not been demonstrated in the literature (Hofstraat and van Brakel 2016). Additional measures include rehabilitation, counselling and support groups (ibid).

Most of these measures can be considered reactive, aiming to counteract or reduce already existing patterns of stigma. Moreover, they are predominantly premised on a biomedical approach and are therefore highly individualistic, aiming for empowerment on a top-down basis that is largely disconnected from the structures that facilitate and legitimise stigma in the first place (Scambler 2009). With COVID-19 still evolving and its longer-term responses beginning to take shape, a more proactive and strategic approach to avoid stigma taking hold at a large scale may be more equitable and effective. Adverse unintended social consequences are to be avoided (Hargreaves et al. 2020) rather than to be grappled with once they have taken hold. Crucially, any policy response needs to acknowledge and address the human rights violations that caused COVID-19 to flourish in the first place, and new violations that have resulted from the disease that allow stigma to reproduce itself and new stigmas to emerge. Without addressing the root causes of violations, the next disease or the next pandemic will repeat the stigma cycle where certain violations cause disease and new violations are created due to disease.

Experiences in relation to other disease-related stigma, including NTDs and HIV, points to the importance of a rights-based and inclusive response. Public health programmes that take a rights-based approach have been shown to 'improve service delivery and enhance equality, equity, inclusiveness, and accountability' (Sun and Amon 2018). The WHO has set out a rights-based approach to NTDs, and that could apply to COVID-19 and other transmissible diseases, which emphasises the principles of participation, non-discrimination, and accountability (WHO 2009). This resonates with a recently published report by the United Nations that places human rights at the centre of the response to COVID-19 and recommends, among others, that policies should guarantee meaningful participation of all sectors of society, that efforts need to reach those most vulnerable and traditionally marginalised, that political leaders and other actors should speak out against discrimination and that freedom of expression is guaranteed in order to hold governments to account (United Nations 2020a). We discuss key considerations for a rights-based and inclusive approach to avoiding and mitigating COVID-19-related stigma within the context of LMICs.

\section{Participation and Inclusion}

Participation and engagement of those affected by COVID-19 will be vital for ensuring that responses are contextualised, localised and responsive to needs (Logie and Turan 2020). In order to avoid that social and economic inequalities are overlooked or compounded, participation needs to cut across intersecting stigmas and fault lines (ibid) such as poverty, ethnicity and age (Hargreaves et al. 2020). Depending on the disease and the context, working with communities and those affected by disease will allow for tailored and community-led responses. For example, the Twa in DRC were incorporated into the response to deliver their own services, and 
communication materials were prepared in the local language (Duda et al. 2018). In Liberia, the inclusion of Ebola survivors is recommended for developing interventions for Ebola-related stigma (Overholt et al. 2018).

In addition, states have an obligation to ensure that laws, policies, and the distribution and delivery of resources, health services, and underlying determinants of health adhere to the principles of equality and non-discrimination. For example, in Sierra Leone, one of the initiatives promoted by the Ebola Response Anthropology Platform was a step-by-step reintegration process in which a social contract was signed by the community and the survivor, including the negative results of the tests, the commitment to pursue infection control practices, and the willingness to welcome the individual (ERAP 2014).

Inclusion should not be taken at face value. Experiences with the response to HIV are instructive in this respect. Inclusive actions, and their associated forms of knowledge about HIV, have themselves often been subject to stigma (Parker and Aggleton 2003). Indeed, still today gender and sexual minority peoples continue to be failed by the international HIV and AIDS response, even as it bears the imprint of sexualities activism. Inclusion may look like it is happening when 'LGBT recognition' is inserted into policy documents and programme guidelines, but substantive and on-the-ground action is called for, based in the lived realities of people of diverse gender and sexuality (Farina et al. 2019).

Inclusion may also be at odds with preventing stigma. Focusing efforts on the inclusion of vulnerable and traditionally marginalised groups requires identification and targeting of such groups. Targeted service delivery inevitably requires labelling and separating out, which in itself is a source of stigmatisation. Service provision premised on the principle of universalism may be powerful in preventing stigma (Roelen 2020). In the case of cholera in Brazil, for example, affected poor communities felt less stigmatised when the target of hygiene promotion activities and communication was universal (rather than specific to the poor communities), and when treatment was given as part of broader services for diarrheal disease or broader health system reinforcement, rather than stigmatising cholera treatment centres (Nations and Monte 1996). At the same time it should be noted that 'shared stigma' can also galvanise positive action within affected groups (Van Laar et al. 2013), helping them to generate solidarity and reclaim identity (Logie and Turan 2020).

The very nature of COVID-19 also poses challenges to a truly inclusive approach. With many of the containment measures focused on physical distancing, the potential for groups to have contact and learn from each other is inevitably hampered. This poses a real conundrum in terms of trying to avoid stigma (Logie and Turan 2020). In line with experiences with SARS, balancing the protection of public health while preventing stigmatisation of groups that are greater risk of contracting or spreading the disease during a rapidly evolving pandemic like COVID-19 is fraught with complexities (Person et al. 2004). Experiences with Ebola in Liberia suggest that minimising social isolation, reintegration in recognition of the end of transmission risk and community-wide economic support serve as pre-emptive approaches for mitigating long-term stigma (Overholt et al. 2018). Indeed, there is evidence that contact is far more effective 
than education in approaches to engage stigmatizers in efforts to reduce diseaserelated stigma. In addition, meaningful contact has been seen as a key pathway to reduce ageism (Christian et al. 2014) and stigma towards those with mental illness (Corrigan et al. 2012). However, the potential viral spread of promoting contact between groups, particularly those that are the most vulnerable, calls for caution. Video contact may serve as an alternative, assuming that the infrastructure is in place, though this may be less effective than face-to-face contact (Corrigan et al. 2012). In addition, contact needs to be 'voluntary, equal, intensive and/ or rewarding, prolonged, or where a number of people are involved' (Pescosolido et al. 2008). If the overall impact of social interactions is "troubling, harmful, or otherwise disturbing,' then contact will most likely have a negative impact (ibid).

\section{Language and Labelling}

Careful use of language is also crucial to a non-discriminatory and inclusive approach. Analogies between disease and war by referring to being 'invaded', to having to 'fight' the virus or having to win the 'battle' feed anxiety and fear of contagion (Logie and Turan 2020) that in turn play into stigma. Common use of the word "vulnerable" could reinforce existing stereotypes of weakness and helplessness, particularly in relation to old age (Nifosi-Sutton 2017). Experiences with NTDs are also instructive in terms of how language can contribute to discriminatory discourse. With the term NTDs spanning almost forty diverse diseases, the words 'neglected' and 'tropical' provide little understanding of the diseases and their health impacts. Instead, they point to a socially constructed category that is reflective of environmental determinism and denial of systematic marginalisation that have allowed these diseases to persist (Shahvisi 2019). Thus, the term and category 'Neglected Tropical Disease' is itself stigmatising, with those suffering from NTDs have been 'cast off' and often experiencing isolation, discrimination, and prejudice in their own communities. These lessons are instructive in terms of language used to categorise flu-like (such as COVID-19) diseases as Asian, and how it gives rise to accompanying discriminatory language that borders on hate-speech. While WHO introduced guidelines in 2015 to halt the naming of diseases in relation to their origin, this does not prevent the association of diseases with their place of origin from popular discourse with politicians and media being common culprits, as is the case for COVID-19 (Nature 2020).

WHO published recommendations regarding appropriate language in relation to COVID-19, highlighting that 'words matter' (WHO 2020). This includes avoiding references to place of origin of the virus, using accurate terminology, and refraining from hyperbolic language that instils fear such as 'plague' (ibid). Referring to those infected with COVID-19 and spreading the virus as 'super spreaders' or those who breach distancing measures as 'intentional murderers' creates a division between the 'moral us' and 'immoral other' (Logie and Turan 2020). Similarly, referring to those who may be infected as 'COVID suspects' may prevent people from seeking healthcare (Sotgiu and Dobler 2020). 


\section{Transparency and Accountability}

It follows that governments and decision makers need to be transparent about the processes and actions that underlie their policy and legal choices. Monitoring and adequate reporting of policies, laws and legal cases is integral to the rights-based approach, also referred to as 'policy surveillance' (Amon 2014). Policy surveillance can provide an analytical tool to assess prevalence and trends, and 'can facilitate the evaluation of health laws, health rights, and accountability mechanisms' (ibid). Rights-based approaches have diverse meanings and are subject to different interpretations, depending on the actors involved (Miller 2010). It is therefore important to consider and make explicit the differing agendas that different actors might have. Doing so lays the foundation for the agreement that 'duty-bearers' meet their obligations and 'rights holders' claim their rights (WHO 2009) according to (1) the availability of facilities, good and services, (2) accessibility based on non-discrimination, physical, economic, and information accessibility, (3) acceptability in regards to medical ethics, culture, and sensitivities to age and gender, (4) quality of services and care both scientifically and medically (ibid).

Bringing the issue of stigma front and centre is crucial to ensure transparent and accountable policy design and implementation. Disease elimination criteria often stipulate that programs 'count' disease burden and morbidity to claim success, while issues like stigma are less tangible and more difficult to address. However, given the early onset and persistence of stigma, seeking to prevent and minimise it during and after disease outbreaks is paramount (Overholt et al. 2018). Doing so necessitates the inclusion of measures to assess and evaluate reductions in stigma. Although the measurement of stigma is complex, the scientific understanding of stigma depends on our capacity to observe and measure it (Link et al. 2004). In a review of healthrelated stigma (Van Brakel 2006) identified five common approaches to measurement, ranging from surveys of attitudes towards those with certain health conditions to interviews with those affected by such health conditions. These tools ought to be located in specific structural and cultural relations to facilitate the important distinction between the consequences of health-related stigma and a cross-cultural theory of health related-stigma (ibid). For example, stigma experiences and practices associated with HIV and NTDs might manifest similarly, yet they are products of entirely different structural drivers and facilitators (Scambler 2009). This exemplifies the need for a biosocial perspective of COVID-19-related stigma, locating it within wider structural and institutional systems as opposed to narrowing understandings to what happens at intra- and interpersonal levels (Logie and Turan 2020).

Pressure towards continued focus and attention can come from communities themselves and, in part, stigma can serve as an important catalyst for doing so. As noted above, affected groups can become agents of change with stigma serving as a catalyst. What we have learned from HIV activism over many years is that struggles are on-going; they require enduring attention, often beyond the mantras of inclusive policy actions or anti-stigma frameworks in the international community. Better conceiving stigma can provide a model of addressing such concerns, helping to promote meaningful health promotion action in terms informed by understandings of the relation between lived experience, structural vulnerabilities 
and (scientific) knowledge communities. Crises typically entail the coming together of experts in attempts to define and resolve a problem to hand-such as a virus and its associated social, political economic effects. What we advocate for here is a conscious broadening of expertise, to include sociological and other experiential knowledge about stigma as it informs life-worlds of inequality within which COVID-19 is intrinsically interconnected.

\section{Conclusion}

It is widely acknowledged that stigma negatively impacts health practices and outcomes, reinforces structural inequalities and undermines equitable development. Emerging evidence suggests that stigma associated with COVID-19 is unfolding rapidly, both manifesting itself as a new stigma and facilitating the expression of existing stigma. Against this backdrop, this article aimed to assess the driving factors and markers of COVID-19-related stigma and to reflect on how the response to COVID-19 can counteract such stigma, particularly in LMICs. We did so by drawing on lessons learned from other disease-related stigma and stigma markers such as old age, disability and poverty in LMICs.

We find that COVID-19-related stigma is already taking hold across LMICs. Rapid spread of misinformation fuels misconceptions and false beliefs about how the virus spreads and who may be 'carriers' of disease. This in turn feeds already strong fears of contagion, offering further fertile ground for stigmatisation of those who have been or are suspected of being infected by the disease or risk infecting others. These dynamics are further reinforced by efforts to contain the virus that hinge on separating and isolating vulnerable groups and infected individuals. Poverty, precarious and unstable living conditions, ethnicity and origin, age and gender present fault lines along which stigma is compounded and reinforced.

A rights-based and inclusive approach to policy that includes the principles of participation, non-discrimination, and accountability is vital. COVID-19 policy and health programmes need to focus on disease elimination or transmission interruption, but they must also 'count what counts' through research into stigma and intersecting vulnerabilities, as well as the conditions which produced the stigma in the first place. Accounting for and monitoring the interplay between factors at the interand intrapersonal, institutional and structural levels is vital for moving beyond a topdown and individualistic approach. Before stigma policy and programmes can be implemented, we must explore what rights violations have contributed to COVID19 stigma and what new violations have emerged due to COVID-19 stigma.

In sum, COVID-19-related stigma in LMICs is a real force to be reckoned with. Not only does it undermine basic levels of dignity, it also causes new types of vulnerabilities, reinforces pre-existing inequalities and ultimately poses a threat to effective containment of COVID-19. In order to be equitable and effective, the response to COVID-19 in LMICs requires the issue of stigma to be placed front and centre to its approach. 
Acknowledgements This work was supported by the National Institute for Health Research (NIHR) Global Health Research Unit on NTDs at Brighton and Sussex Medical School using Official Development Assistance (ODA) funding. The views expressed here are those of the author(s) and not necessarily those of the NIHR or the Department of Health and Social Care.

\section{Compliance with Ethical Standards}

Conflict of interest On behalf of all authors, the corresponding author states that there is no conflict of interest.

\section{References}

Ahinkorah, Bright Opoku, Edward Kwabena Ameyaw, John Elvis Hagan, Abdul-Aziz. Seidu, and Thomas Schack. 2020. Rising Above Misinformation or Fake News in Africa: Another Strategy to Control COVID-19 Spread. Frontiers in Communication 5: 45. https://doi.org/10.3389/fcomm .2020 .00045 .

Amon, Joseph. 2014. Law, Human Rights, and Health Databases: A Roundtable Discussion. Health and Human Rights Journal (blog). https://www.hhrjournal.org/2014/09/law-human-rights-and-healt h-databases-a-roundtable-discussion/. Accessed 11 Sept 2014.

Armario, Christine. 2020. 'Hidden Suffering of Coronavirus: Stigma, Blaming, Shaming'. Medical Xpress. https://medicalxpress.com/news/2020-04-hidden-coronavirus-stigma-blaming-shami ng.html. Accessed 4 April 2020.

Ayalon, Liat. 2020. There Is Nothing New Under the Sun: Ageism and Intergenerational Tension in the Age of the COVID-19 Outbreak. International Psychogeriatrics. https://doi.org/10.1017/S1041 610220000575.

Bagcchi, Sanjeet. 2020. Stigma During the COVID-19 Pandemic. The Lancet Infectious Diseases 20 (7): 782. https://doi.org/10.1016/S1473-3099(20)30498-9.

Barnett-Howell, Zachary, and Ahmed Mushfiq Mobarak. 2020. Should Low-Income Countries Impose the Same Social Distancing Guidelines as Europe and North America to Halt the Spread of COVID19? New Haven: Yale University.

Barua, Zapan, Sajib Barua, Salma Aktar, Najma Kabir, and Mingze Li. 2020. Effects of Misinformation on COVID-19 Individual Responses and Recommendations for Resilience of Disastrous Consequences of Misinformation. Progress in Disaster Science. https://doi.org/10.1016/j.pdisa s.2020.100119.

Basu, Kaushik. 2020. 'Who’s Afraid of COVID-19?' Project Syndicate. https://www.project-syndicate. org/commentary/developing-countries-fear-drives-policy-mistakes-by-kaushik-basu. Accessed 6 May 2020.

BBC News. 2020. Coronavirus: Fact-Checking Fake Stories in Africa-BBC News. https://www.bbc. co.uk/news/53684037.

BBC News Africa. 2020. Covid-19 in Africa: Fighting Fake News About Coronavirus. Covid-19 in Africa: Fighting Fake News about Coronavirus. https://www.bbc.co.uk/news/resources/idt-e7e3a cde-9cdf-4b53-b469-ef6e87a66411.

Bos, Arjan E. R., John B. Pryor, Glenn D. Reeder, and Sarah E. Stutterheim. 2013. Stigma: Advances in Theory and Research. Basic and Applied Social Psychology 35 (1): 1-9.

Boyce, Paul., and Cataldo, Fabian. 2019 'MSM-ing' as a networking concept: Becoming a global health category. Medicine Anthropology Theory. ISSN 2405-691X.

Briggs, Charles L., and Clara Mantini-Briggs. 2003. Stories in the Time of Cholera. Oakland: University of California Press.

Brooks, Samantha K., Rebecca K. Webster, Louise E. Smith, Lisa Woodland, Simon Wessely, Neil Greenberg, and Gideon James Rubin. 2020. The Psychological Impact of Quarantine and How to Reduce It: Rapid Review of the Evidence. The Lancet 395 (10227): 912-920.

Buford, Thomas W. 2016. Hypertension and Aging. Ageing Research Reviews 26 (March): 96-111.

Buist, A. Sonia., Mary Ann McBurnie, William M. Vollmer, Suzanne Gillespie, Peter Burney, David M. Mannino, Ana M. B. Menezes, et al. 2007. International Variation in the Prevalence of COPD (the BOLD Study): A Population-Based Prevalence Study. The Lancet 370 (9589): 741-750. 
Castro, Arachu, and Paul Farmer. 2005. Understanding and Addressing AIDS-Related Stigma: From Anthropological Theory to Clinical Practice in Haiti. American Journal of Public Health 95 (1): 53-59.

Chan, Kit Yee, Yi. Yang, Kong-Lai. Zhang, and Daniel D. Reidpath. 2007. Disentangling the Stigma of HIV/AIDS from the Stigmas of Drugs Use, Commercial Sex and Commercial Blood Donation-A Factorial Survey of Medical Students in China. BMC Public Health 7 (1): 280.

Christian, Julie, Rhiannon Turner, Natasha Holt, Michael Larkin, and Joseph Howard Cotler. 2014. Does Intergenerational Contact Reduce Ageism: When and How Contact Interventions Actually Work. Journal of Arts and Humanities. https://doi.org/10.18533/journal.v3i1.278.

Chuki, Sonam. 2019. Being LGBT: Their Status and Rights in Bhutan. Australian Journal of Asian Law 20 (1): 1-8.

Correia, Jorge César, Alain Golay, Sarah Lachat, Suman Bahadur Singh, Varsha Manandhar, Nilambar Jha, François Chappuis, David Beran, and on behalf of the COHESION Project. 2019. "If You Will Counsel Properly with Love, They Will Listen": A Qualitative Analysis of Leprosy Affected Patients' Educational Needs and Caregiver Perceptions in Nepal. PLoS ONE 14(2): e0210955.

Corrigan, Patrick W., Scott B. Morris, Patrick J. Michaels, Jennifer D. Rafacz, and Nicolas Rüsch. 2012. Challenging the Public Stigma of Mental Illness: A Meta-Analysis of Outcome Studies. Psychiatric Services 63 (10): 963-973. https://doi.org/10.1176/appi.ps.201100529.

Coudin, Geneviève, and Theodore Alexopoulos. 2010. "Help Me! I'm Old!" How Negative Aging Stereotypes Create Dependency among Older Adults. Aging \& Mental Health 14 (5): 516-523.

Cuan-Baltazar, Jose Yunam, Maria José Muñoz-Perez, Carolina Robledo-Vega, Maria Fernanda PérezZepeda, and Elena Soto-Vega. 2020. Misinformation of COVID-19 on the Internet: Infodemiology Study. JMIR Public Health Surveill 6 (2): e18444.

Dahab, Maysoon, Kevin van Zandvoort, Stefan Flasche, Abdihamid Warsame, Paul B. Spiegel, Ronald Waldman, and Francesco Checchi. 2020. 'COVID-19 Control in Low-Income Settings and Displaced Populations: What Can Realistically Be Done?' London: London School of Hygiene and Tropical Medicine. https://www.lshtm.ac.uk/newsevents/news/2020/covid-19-control-low-incom e-settings-and-displaced-populations-what-can.

Devereux, Stephen, Jeremy Lind, Keetie Roelen, and Rachel Sabates-Wheeler. 2020. 'Covid-19 and Social Protection Needs: Who Are the Most Vulnerable?' Covid-19 and Social Protection Needs: Who Are the Most Vulnerable? (blog). https://www.ids.ac.uk/opinions/covid-19-and-social-prote ction-needs-who-are-the-most-vulnerable/. Accessed 7 May 2020.

Duda, R., L. Alcayna-Stevens, and J. Bedford. 2018. Key Considerations: Engaging TWA Communities in Équateur Province. Brighton: UNICEF, IDS and Anthrologica.

Earnshaw, Valerie A., Laramie R. Smith, Stephenie R. Chaudoir, K. Rivet Amico, and Michael M. Copenhaver. 2013. HIV Stigma Mechanisms and Well-Being Among PLWH: A Test of the HIV Stigma Framework. AIDS and Behavior 17 (5): 1785-1795.

ERAP. 2014. Ebola Survivors: Using a Stepwise Re-Integration Process to Establish Social Contracts between Survivors and Their Home Communities. Intervention Concept Note. Brighton: Institute of Development Studies.

Erku, Daniel A., Sewunet A. Belachew, Solomon Abrha, Mahipal Sinnollareddy, Jackson Thomas, Kathryn J. Steadman, and Wubshet H. Tesfaye. 2020. When Fear and Misinformation Go Viral: Pharmacists' Role in Deterring Medication Misinformation During the "infodemic" Surrounding COVID-19. Research in Social and Administrative Pharmacy. https://doi.org/10.1016/j.sapha rm.2020.04.032.

Falk, Gerhard. 2001. Stigma: How We Treat Outsiders. Amherst, NY: Prometheus Books.

Farina, Nicolas., Asghar, Zaidi, Rosalind, Willis., and Sara, Balouch. 2019. Attitudes, knowledge and beliefs about dementia: Focus group discussions with Pakistani adults in Karachi and Lahore. Ageing and Society, 1-16. https://doi.org/10.1017/S0144686X19000862

Gentilini, Ugo, Mohamed Almenfi, Pamela Dale, Ana Veronica Lopez, Ingrid Veronica Mujica, Rodrigo Quintana, and Usama Zafar. 2020. Social Protection and Jobs Responses to COVID-19: A RealTime Review of Country Measures. "Living paper" Version 13. Washington, DC: World Bank.

Goffman, Erving. 1963. Stigma: Notes on the Management of Spoiled Identity. New York: Simon and Schuster

Griffin, Jo, and Daniela Antara Rivera. 2020. "Separation by Sex": Gendered Lockdown Fuelling Hate Crime on Streets of Bogotá'. The Guardian, 8 May 2020, sec. Global Development. https://www. theguardian.com/global-development/2020/may/08/separation-by-sex-gendered-lockdown-fuell ing-hate-on-streets-of-bogota. 
Gyasi, Razak M. 2020. Fighting COVID-19: Fear and Internal Conflict Among Older Adults in Ghana. Journal of Gerontological Social Work. https://doi.org/10.1080/01634372.2020.1766630.

Hargreaves, James, Calum Davey, James Hargreaves, Calum Davey, Judith Auerbach, Jamie Blanchard, Virginia Bond, et al. 2020. Three Lessons for the COVID-19 Response from Pandemic HIV. The Lancet HIV 7 (5): e309-e311.

HelpAge International. 2018. Freedom to Decide for Ourselves. London: HelpAge International.

Hewlett, Barry, and Bonnie Hewlett. 2008. Ebola, Culture and Politics: The Anthropology of an Emerging Disease. https://www.ebola-anthropology.net/evidence/ebola-culture-and-politics-the-anthr opology-of-an-emerging-disease/.

Hofstraat, Karlijn, and Wim H. van Brakel. 2016. Social Stigma towards Neglected Tropical Diseases: A Systematic Review. International Health 8 (suppl_1): i53-70.

Hong, Yan, Xiaoming Li, Bonita Stanton, Xiaoyi Fang, Danhua Lin, Jing Wang, Rong Mao, and Hongmei Yang. 2008. Expressions of HIV-Related Stigma among Rural-to-Urban Migrants in China. AIDS Patient Care and STDs 22 (10): 823-831.

Hunt, Jennifer, Katherine Bristowe, Sybille Chidyamatare, and Richard Harding. 2017. "They Will Be Afraid to Touch You": LGBTI People and Sex Workers' Experiences of Accessing Healthcare in Zimbabwe-An in-Depth Qualitative Study. BMJ Global Health 2 (2): e000168.

Jordan, Rachel E., Peymane Adab, and K.K. Cheng. 2020. Covid-19: Risk Factors for Severe Disease and Death. BMJ 3: 68. https://doi.org/10.1136/bmj.m1198.

Jung, Seong Hye, Hee Won Han, Hyeonseok Koh, Yu. Soo-Young, Nobutoshi Nawa, Ayako Morita, Ken Ing Cherng. Ong, Masamine Jimba, and Oh. Juhwan. 2020. Patients Help Other Patients: Qualitative Study on a Longstanding Community Cooperative to Tackle Leprosy in India. PLOS Neglected Tropical Diseases 14 (1): e0008016.

Kabole, Atetwe Lydiah, Felix Nguzo Kioli, and Kennedy Onkware. 2013. The Social Context of Abuse of Elderly People in Emuhaya District, Kenya. Sociology and Anthropology 1 (2): 76-86.

Karamouzian, Mohammad, and Celestin Hategekimana. 2014. Ebola Treatment and Prevention are Not the Only Battles: Understanding Ebola-Related Fear and Stigma. International Journal of Health Policy and Management 4 (1): 55-56.

Kelley, Maureen, Rashida A. Ferrand, Kui Muraya, Simukai Chigudu, Sassy Molyneux, Madhukar Pai, and Edwine Barasa. 2020. An Appeal for Practical Social Justice in the COVID-19 Global Response in Low-Income and Middle-Income Countries. The Lancet Global Health. https://doi. org/10.1016/S2214-109X(20)30249-7.

Krishnatray, Pradeep. 2020. COVID-19 Is Leading to a New Wave of Social Stigma. The Wire. https:// thewire.in/society/covid-19-social-stigma. Accessed 12 May 2020.

Lee, Sing, Lydia Y. Y. Chan, Annie M. Y. Chau, Kathleen P. S. Kwok, and Arthur Kleinman. 2005. The Experience of SARS-Related Stigma at Amoy Gardens. Social Science \& Medicine 61 (9): 2038-2046.

Lerman, S., B. Ostrach, and M. Singer. 2017. Foundations of Biosocial Health: Stigma and Illness Interactions. London: Lexington.

Lind, Jeremy, Keetie Roelen, and Rachel Sabates-Wheeler. 2020. Social Protection and Building Back Better. Positioning Paper. Brighton: Institute of Development Studies and Irish Aid.

Link, Bruce G., and Jo. C. Phelan. 2001. Conceptualizing Stigma. Annual Review of Sociology 27 (1): 363-385.

Link, Bruce G., Lawrence H. Yang, Jo. C. Phelan, and Pamela Y. Collins. 2004. Measuring Mental Illness Stigma. Schizophrenia Bulletin 30 (3): 511-541.

Lloyd-Sherlock, Peter G., Shah Ebrahim, Martin McKee, and Martin James Prince. 2016. Institutional Ageism in Global Health Policy. BMJ 354: 14514.

Logie, Carmen H., and Janet M. Turan. 2020. 'How Do We Balance Tensions Between COVID-19 Public Health Responses and Stigma Mitigation? Learning from HIV Research. AIDS and Behavior. https ://doi.org/10.1007/s10461-020-02856-8.

Lynteris, Christos. 2019. Introduction: Infectious Animals and Epidemic Blame. In Framing Animals as Epidemic Villains: Histories of Non-Human Disease Vectors, ed. Christos Lynteris, 1-25. St Andrews: University of St Andrews.

Mahajan, Anish P., Jennifer N. Sayles, Vishal A. Patel, Robert H. Remien, Sharif R. Sawires, Daniel J. Ortiz, Greg Szekeres, and Thomas J. Coates. 2008. Stigma in the HIV/AIDS Epidemic: A Review of the Literature and Recommendations for the Way Forward. AIDS 22 (Suppl 2): S67-79. 
Maia, Fátima Beatriz., Enéas Rangel. Teixeira, Gislaine Valeria Silva, and Maria Katia Gomes. 2016. The Use of Assistive Technology to Promote Care of the Self and Social Inclusion in Patients with Sequels of Leprosy. PLOS Neglected Tropical Diseases 10 (4): e0004644.

Mamun, Mohammed A., and Mark D. Griffiths. 2020. First COVID-19 Suicide Case in Bangladesh Due to Fear of COVID-19 and Xenophobia: Possible Suicide Prevention Strategies. Asian Journal of Psychiatry 51 (April): 102073-102073. https://doi.org/10.1016/j.ajp.2020.102073.

Miller, Hannah. 2010. From "Rights-Based" to "Rights-Framed" Approaches: A Social Constructionist View of Human Rights Practice. The International Journal of Human Rights 14 (6): 915-931.

Muela, Ribera, Koen Peeters Joan, Elizabeth Toomer Grietens, and Susanna Hausmann-Muela. 2009. A Word of Caution against the Stigma Trend in Neglected Tropical Disease Research and Control. PLOS Neglected Tropical Diseases 3 (10): e445.

Nations, Marilyn K., and Cristina M.G. Monte. 1996. "I'm Not Dog, No!": Cries of Resistance against Cholera Control Campaigns. Social Science \& Medicine 43(6): 1007-1024.

Nature. 2020. End Coronavirus Stigma Now. Nature 580:165. https://doi.org/10.1038/d41586-020$01009-0$.

NCCDH. 2020. 'Stigma, Discrimination, Health Impacts and COVID-19'. National Collaborating Centre for Determinants of Health (blog). https://nccdh.ca/blog/entry/stigma-discriminationhealth-impacts-and-covid-19. Accessed 16 Mar 2020.

Nifosi-Sutton, I. (2017). The protection of vulnerable groups under international human rights law. Taylor \& Francis: Abingdon, UK.

O'Hara, Mary. 2020. The Shame Game. Overturning the Toxic Poverty Narrative. Bristol: Policy Press.

Oryem, Robin. 2020. Xenophobia and Behavioural Responses to COVID-19 in Uganda. https://blogs .lse.ac.uk/africaatlse/2020/05/01/xenophobia-racism-ebola-behavioural-change-covid19-uganda/. Accessed 1 May 2020.

Overholt, Luc, David Alain Wohl, William A. Fischer II, Daniel Westreich, Sam Tozay, Edwina Reeves, Korto Pewu, et al. 2018. Stigma and Ebola Survivorship in Liberia: Results from a Longitudinal Cohort Study. PLoS ONE 13 (11): e0206595.

Pan, Daniel, Shirley Sze, Jatinder S. Minhas, Mansoor N. Bangash, Nilesh Pareek, Pip Divall, Caroline ML.. Williams, et al. 2020. The Impact of Ethnicity on Clinical Outcomes in COVID-19: A Systematic Review. EClinicalMedicine. https://doi.org/10.1016/j.eclinm.2020.100404.

Parker, R., and P. Aggleton. 2003. HIV and AIDS-Related Stigma and Discrimination: A Conceptual Framework and Implications for Action. Social Science \& Medicine 57 (1): 13-24.

Person, Bobbie, Francisco Sy, Kelly Holton, Barbara Govert, Arthur Liang, and National Center for Inectious Diseases/SARS Community Outreach Team. 2004. Fear and Stigma: The Epidemic within the SARS Outbreak. Emerging Infectious Diseases 10 (2): 358-363.

Pescosolido, Bernice A., Jack K. Martin, Annie Lang, and Sigrun Olafsdottir. 2008. Rethinking Theoretical Approaches to Stigma: A Framework Integrating Normative Influences on Stigma (FINIS). Social Science \& Medicine 67 (3): 431-440. https://doi.org/10.1016/j.socscimed.2008.03.018.

Pryce, Joseph, Hayley E. Mableson, Ramesh Choudhary, Basu Dev Pandey, Dambar Aley, Hannah Betts, Charles D. Mackenzie, Louise A. Kelly-Hope, and Hugh Cross. 2018. Assessing the Feasibility of Integration of Self-Care for Filarial Lymphoedema into Existing Community Leprosy Self-Help Groups in Nepal. BMC Public Health 18 (1): 201.

Rafi, Muhammad Shaban. 2020. Language of COVID-19: Discourse of Fear and Sinophobia. Social Sciences \& Humanities Open. https://doi.org/10.2139/ssrn.3603922.

Ripoll, Santiago. 2017. Contextual Factors Shaping Cholera Transmission and Treatment-Seeking in Somalia and the Somali Region of Ethiopia. Social Sciences in Action. Brighton: Institute of Development Studies.

Ripoll, Santiago, Ingrid Gercama, Theresa Jones, and Annie Wilkinson. 2018. Social Science in Epidemics: Ebola Virus Disease Lessons Learned. Brighton: Institute of Development Studies.

Rohrwerder, B. 2018. Disability Stigma in Developing Countries. K4D Helpdesk Report. Brighton: Institute of Development Studies.

Roelen, K. 2020. Receiving social assistance in low- and middle-income countries: Negating shame or producing stigma? Journal of Social Policy 49 (4): 705-723.

Scambler, Graham. 2009. Health-Related Stigma. Sociology of Health \& Illness 31 (3): 441-455.

Shahvisi, Arianne. 2019. Tropicality and Abjection: What Do We Really Mean by "Neglected Tropical Diseases"? Developing World Bioethics 19 (4): 224-234. 
Soi, Catherine. 2020. Stigma, Fears of Quarantine Hinder Kenya's COVID-19 Fight. Al Jazeera. https ://www.aljazeera.com/news/2020/05/stigma-fears-quarantine-hinder-kenyas-covid-19-fight-20051 5103153190.html. Accessed 15 May 2020.

Sotgiu, Giovanni, and Claudia C. Dobler. 2020. Social Stigma in the Time of Coronavirus. European Respiratory Journal. https://doi.org/10.1183/13993003.02461-2020.

SSHAP. 2020. One Size Does Not Fit All: COVID-19 Responses Across African Settings. Brighton: Social Science in Humanitarian Action Platform (SSHAP).

Stangl, Anne L., Valerie A. Earnshaw, Carmen H. Logie, Wim van Brakel, Leickness C. Simbayi, Iman Barré, and John F. Dovidio. 2019. The Health Stigma and Discrimination Framework: A Global, Crosscutting Framework to Inform Research, Intervention Development, and Policy on HealthRelated Stigmas. BMC Medicine 17 (1): 31.

Suastika, Ketut, Pande Dwipayana, Made Siswadi Semadi, and R.A. Tuty Kuswardhani. 2012. Age Is an Important Risk Factor for Type 2 Diabetes Mellitus and Cardiovascular Diseases. Glucose Tolerance. https://doi.org/10.5772/52397.

Sumner, Andy, Eduardo Ortiz-Juarez, and Chris Hoy. 2020. Precarity and the Pandemic: COVID-19 and Poverty Incidence, Intensity, and Severity in Developing Countries. WIDER Working Paper 2020/77. Helsinki: UNU-WIDER.

Sun, Nina, and Joseph J. Amon. 2018. Addressing Inequity. Health and Human Rights 20 (1): 11-25.

Taylor, Luke. 2020. Covid-19 Misinformation Sparks Threats and Violence against Doctors in Latin America. BMJ 370 (August): m3088. https://doi.org/10.1136/bmj.m3088.

Tyler, Imogen, and Tom Slater. 2018. Rethinking the Sociology of Stigma. The Sociological Review 66 (4): 721-743.

UNAIDS. 2020. 'Stigma, Discrimination, and Gender-Based Violence in the COVID-19 Pandemic: Young Key Populations in Asia and the Pacific'. https://unaids-ap.org/2020/08/11/stigma-discr imination-and-gender-based-violence-in-the-covid-19-pandemic-young-key-populations-in-asiaand-the-pacific/.

UN Department of Global Communications. 2020. COVID-19: UN Counters Pandemic-Related Hate and Xenophobia. United Nations COVID-19 Response. https://www.un.org/en/coronavirus/covid -19-un-counters-pandemic-related-hate-and-xenophobia. Accessed 11 May 2020.

United Nations. 2020. COVID-19 and Human Rights. We All in This Together. New York: United Nations.

United Nations. 2020. COVID-19 and the Human Rights of LGBTI People. New York: United Nations, Office of the High Commissioner Human Rights.

Usher, Ann Danaiya. 2020. COVID-19 Vaccines for All? The Lancet 395 (10240): 1822-1823.

Brakel, Van, and H. Wim. 2006. Measuring Health-Related Stigma-A Literature Review. Psychology, Health \& Medicine 11 (3): 307-334.

Laar, Van, Belle Derks Colette, and Naomi Ellemers. 2013. Motivation for Education and Work in Young Muslim Women: The Importance of Value for Ingroup Domains. Basic and Applied Social Psychology 35 (1): 64-74.

Van Oorschot, W.J.H. 2002. Who Should Get What, and Why? On Deservingness Criteria and the Conditionality of Solidarity among the Public. Policy and Politics: Studies of Local Government and Its Services 28 (1): 33-48.

Verma, S., Mythily Subramaniam, Jp. Deslypere, Ek. Teo, and Sa. Chong. 2004. Post-SARS Psychological Morbidity and Stigma Among General Practitioners and Traditional Chinese Medicine Practitioners in Singapore. Annals of the Academy of Medicine, Singapore 33 (January): 743-748.

Wajahat, Hussain. 2020. Role of Social Media in COVID-19 Pandemic. The International Journal of Frontier Sciences 4: 2.

Walker, David. 2014. Shame and Poverty. Oxford: Oxford University Press.

Weiskopf, Daniela, Birgit Weinberger, and Beatrix Grubeck-Loebenstein. 2009. The Aging of the Immune System. Transplant International 22 (11): 1041-1050.

Wilkinson, Annie. 2020. Local Response in Health Emergencies: Key Considerations for Addressing the COVID-19 Pandemic in Informal Urban Settlement. Environment and Urbanization. https://doi. org/10.1177/0956247820922843.

WHO. 2020. Social Stigma Associated with COVID-19. A Guide to Preventing and Addressing Social Stigma. Geneva: IFRC, UNICEF, WHO. https://www.who.int/docs/default-source/coronaviruse/ covid19-stigma-guide.pdf.

World Health Organization; Office of the High Commissioner for Human Rights (OHCHR). 2009. A Human Rights-Based Approach to Health. Geneva: WHO. 
Wu, Zunyou, and Jennifer M. McGoogan. 2020. Characteristics of and Important Lessons From the Coronavirus Disease 2019 (COVID-19) Outbreak in China: Summary of a Report of 72314 Cases From the Chinese Center for Disease Control and Prevention. JAMA 323 (13): 1239-1242.

Xi, W., W. Xu, X. Zhang, and L. Ayalon. 2020. A thematic analysis of weibo topics (Chinese twitter hashtags) regarding older adults during the COVID-19 outbreak. The Journals of Gerontology: Series B, gbaa148. https://doi.org/10.1093/geronb/gbaa148.

Xiang, Xiaoling, Lu. Xuan, Alex Halavanau, Jia Xue, Yihang Sun, Patrick Ho Lam. Lai, and Wu. Zhenke. 2020. Modern Senicide in the Face of a Pandemic: An Examination of Public Discourse and Sentiment about Older Adults and COVID-19 Using Machine Learning. The Journals of Gerontology. Series B, Psychological Sciences and Social Sciences. https://doi.org/10.1093/geronb/gbaa128.

Zeldenryk, Lynne Michelle, Marion Gray, Richard Speare, Susan Gordon, and Wayne Melrose. 2011. The Emerging Story of Disability Associated with Lymphatic Filariasis: A Critical Review. PLOS Neglected Tropical Diseases 5 (12): e1366.

Zhou, Fei, Yu. Ting, Du. Ronghui, Guohui Fan, Ying Liu, Zhibo Liu, Jie Xiang, et al. 2020. Clinical Course and Risk Factors for Mortality of Adult Inpatients with COVID-19 in Wuhan, China: A Retrospective Cohort Study. The Lancet 395 (10229): 1054-1062.

Publisher's Note Springer Nature remains neutral with regard to jurisdictional claims in published maps and institutional affiliations.

\section{Affiliations}

\section{Keetie Roelen ${ }^{1}\left[\right.$ (D) Caroline Ackley $^{2} \cdot$ Paul Boyce $^{3} \cdot$ Nicolas Farina $^{4}$. Santiago Ripoll ${ }^{1}$}

Caroline Ackley

c.ackley@bsms.ac.uk

Paul Boyce

p.boyce@sussex.ac.uk

Nicolas Farina

N.Farina@sussex.ac.uk

Santiago Ripoll

s.ripoll@ids.ac.uk

1 Institute of Development Studies (IDS), University of Sussex, Library Road, Brighton BN1 9RE, UK

2 Global Health Research Unit, Brighton and Sussex Medical School, University of Sussex, Brighton BN1 9PX, UK

3 School of Global Studies, University of Sussex, Brighton BN1 9SJ, UK

4 Centre for Dementia Studies, Brighton and Sussex Medical School, University of Sussex, Brighton BN1 9PX, UK 